\title{
Perceptions of Couples Who Use Jadelle Implant in Blantyre District, Malawi
}

\author{
Brima Osaio Kamara*, Rachel Rodriguez, Genesis Chorwe-Sungani, Angela Chimwaza \\ Kamuzu College of Nursing, University of Malawi, Blantyre, Malawi \\ Email: "brimaosaiokamara@gmail.com
}

Received 21 September 2015; accepted 13 November 2015; published 16 November 2015

Copyright (C) 2015 by authors and Scientific Research Publishing Inc.

This work is licensed under the Creative Commons Attribution International License (CC BY). http://creativecommons.org/licenses/by/4.0/

(c) (i) Open Access

\begin{abstract}
Malawi has a high total fertility rate of 5.7 per woman and Jadelle implant may be an ideal option for couples who want to practice family planning. Jadelle is a long term contraceptive which is inserted just under the skin of a woman's upper, inner arm by a nurse or midwife and prevents a woman from getting pregnant for a period of five years. But the use of Jadelle for family planning depends on perceptions of couples. The purpose of this study was to explore the perceptions of couples who choose Jadelle as their family planning method at a Central Hospital in Blantyre district. This study used a descriptive qualitative design. A purposive sample of 5 couples was used. Ethical clearance was granted by relevant authorities. Data was analysed through content analysis. The findings showed that the following nine themes emerged from the qualitative data: 1) men and women perspectives about mode of action of Jadelle; 2 ) knowledge about effectiveness and efficacy of Jadelle among men and women; 3) sources of information about Jadelle; 4) information given to Jadelle users by providers; 5) benefits of Jadelle; 6) challenges associated with Jadelle; 7) myths associated with Jadelle; 8) attitudes of providers of Jadelle and 9) role played by men regarding use of Jadelle. In conclusion, this study found that both men and women generally lacked knowledge of Jadelle. Men play a vital role when couples are choosing contraceptives. Every opportunity should be utilised at antenatal, postnatal and family planning clinics to teach individuals about family planning. This may allow women and men to make informed choices about the use of Jadelle.
\end{abstract}

\section{Keywords}

Perception, Jadelle, Couples, Family Planning

\section{Introduction}

Malawi has a high total fertility rate of 5.7 per woman [1] and Jadelle implant may be an ideal option for ${ }^{*}$ Corresponding author.

How to cite this paper: Kamara, B.O., Rodriguez, R., Chorwe-Sungani, G. and Chimwaza, A. (2015) Perceptions of Couples Who Use Jadelle Implant in Blantyre District, Malawi. Open Journal of Nursing, 5, 994-1003. 
couples who want to practice family planning. Jadelle is a long term contraceptive which is inserted just under the skin of a woman's upper, inner arm by a nurse or midwife [2] and prevents a woman from getting pregnant for a period of five years. The use of Jadelle for family planning depends on perceptions of couples. Some men and women perceive that using contraceptive methods helps them to live a healthy life and participate in development activities. Others perceive that a man becomes weak (impotent) if he sleeps with a woman who is using contraceptives such as Jadelle [3]. Similarly, men and women may also perceive that women who use modern family planning methods to reduce the number of children God intended for them and they will be punished with infertility on reincarnation [4]. This shows that perceptions may encourage or discourage couples from using Jadelle and other family planning methods. The misperceptions about contraceptive use and little perceived risk of pregnancy are some of the reasons for unplanned pregnancy [5]. This may be true for Malawi where unplanned pregnancies are common. These unplanned pregnancies mostly end up in unsafe abortions which lead to increased deaths of women.

It is evident that $17 \%$ of maternal deaths are due to unsafe abortion globally [6]. Nonetheless, the effective use of contraceptives saves women's lives and preserves their health by protecting them from the health risks of frequent childbirth and unsafe abortion [7]. Most maternal deaths in Malawi are due to complications of unsafe abortions from unwanted pregnancies that can have been prevented through effective use of contraceptive methods. The rate of abortions in Malawi is high at 38 per 1000 women of reproductive age [8]. Besides that, maternal mortality rate for the country (675/100,000 live births) is amongst the highest in the world [1]. This was corroborated by Khunga and Lupickwho asserted that 807 women per 100,000 died in child birth in Malawi in 2010 [8]. These high levels of maternal mortality may be reduced by encouraging couples to use Jadelle which effectively prevents unplanned pregnancies. However, Jadelle is the least used contraceptive method at $0.3 \%$ [1] and most women use short term contraceptive methods which may sometimes be out of stock in the country [9]. Couples may not use Jadelle because they may have fear of perceived complications. There is evidence that women have concerns about family planning methods, including fear of side effects from hormonal methods [7]. Furthermore, a woman may feel that she has or lacks control over her own fertility due to social constructs of gender roles and expectations in her society [10].

Gender inequality, for example, may determine who has access to family planning information, which holds the power to negotiate contraceptive use or to withhold sex, who decides on family size, and who controls economic resources to obtain family planning related health services. These hurdles vary from culture to culture, yet they exist throughout the world and can often lead to negative family planning health outcomes. These problems are partly dealt with in Malawi by the Sexual Reproductive Health and Rights Policy for Malawi which proposes that individuals and couples have a right to decide freely and responsibly the number, spacing and timing of children and shall be provided with the means to do so without coercion [11]. The policy also provides for the availability of long lasting and permanent methods of contraceptives such as Jadelle at all levels of health care services in the country. This is vital for Malawi where stock-outs of short-term contraceptives are common and Jadelle offers a vital option for couples who want to delay or space child-bearing [9]. Nonetheless, the perceptions of men and women towards the use of Jadelle as a family planning method are not well documented in Malawi. Therefore, this study was conducted to explore the perceptions of couples who choose Jadelle as their family planning method at Queen Elizabeth Central Hospital in Blantyre district.

\section{Methodology}

\subsection{Design}

This study used descriptive design employing a qualitative method to explore perceptions of couples who choose Jadelle implant as their family planning method.

\subsection{Setting}

Setting for this study was a family planning clinic at Queen Elizabeth Central Hospital in Blantyre district.

\subsection{Sample and Sampling}

Target population was all couples who were using Jadelle implant. The sample comprised of 5 couples (5 men and 5 women) who were purposively sampled because participants were required to be experientially fit for the 
study. Qualitative inquiry is deliberately biased hence selection was based on the participants' experience that fits the research questions [12]. The decision to interview 5 couples only was based on the fact that the data became saturated. In this study, the researcher identified the participants at the Family Planning Clinic when they were attending check-up visits. The inclusion criteria were as follows: 1) being a married couple in which a woman is on Jadelle implant or had used it before; 2) expressing willingness to participate in the study and 3) being able to communicate in Chichewa. Couples who accepted to participate in the study were asked to sign a written consent.

\subsection{Data Collection}

An interview guide was used to collect data from the participants through in-depth interviews. Female participants were interviewed by a female research assistant while males were interviewed by a male research assistant considering the sensitivity of some issues that may come up during interviews. The length of each interview was between 30 and 45 minutes. Participants were interviewed in Chichewa because it is the most widely spoken language in Malawi. The individual interviews were conducted face to face in a private room at the family planning clinic. Couples were allowed to receive the services from the service provider before they were interviewed. Interviews were audio recorded and later transcribed and typed verbatim. Transcripts were assigned code numbers for identification.

\subsection{Data Analysis}

The collected data were analysed through content analysis. Themes were derived by analysis of words so that word repetitions, key indigenous terms, and key words in the contexts were identified. In addition themes were identified through a careful reading of larger blocks of texts, comparing and contrasting information and searching for missing information. Themes were also developed by conducting a comparative analysis of concepts coded in different participants group or setting codes. Demographic data was analysed manually using descriptive statistics.

\subsection{Ethical Considerations}

Ethical approval was granted by College of Medicine Research and Ethics Committee (COMREC) and institutional clearance was obtained from Director of Queen Elizabeth Central Hospital prior to data collection to ensure participants' protection. Participants volunteered to take part in the study and they gave a written consent. They were also assured that they would not be denied health care services because of their withdrawal or refusal to participate in the study.

\subsection{Limitations of This Study}

The limitation of this study is that a small sample size was used which might have limited the depth of information which was gathered in this study.

\section{Findings}

Demographic characteristics of participants of this study are presented in Table 1. The following nine themes emerged from the qualitative data: 1) men and women perspectives about mode of action of Jadelle; 2) knowledge about effectiveness and efficacy of Jadelle among men and women; 3) sources of information about Jadelle; 4) information given to Jadelle users by providers; 5) benefits of Jadelle; 6) challenges associated with Jadelle; 7) myths associated with Jadelle; 8) attitudes of providers of Jadelle and 9) role played by men regarding use of Jadelle.

\subsection{Theme 1: Men and Women Perspectives about Mode of Action of Jadelle}

The findings of this study revealed that men and women have various perspectives about the mode of action of Jadelle. Some participants linked the mode of action to their personal care or various perspectives. Other participants linked it to their personal agreement with the kind of care or knowledge given to them by providers. One participant said that Jadelle makes semen to be weak, so that no fertilization takes place. Similar views were 
Table 1. Demographic characteristics of participants.

\begin{tabular}{|c|c|c|c|}
\hline Demographic characteristics & Male & Female & Total \\
\hline & $\mathrm{n}$ & $\mathrm{n}$ & $\mathrm{n}$ \\
\hline \multicolumn{4}{|l|}{ Age group } \\
\hline $25-30$ & 1 & 3 & 4 \\
\hline $31-35$ & 2 & 2 & 4 \\
\hline $36-40$ & 2 & 0 & 2 \\
\hline \multicolumn{4}{|l|}{ Education level } \\
\hline PSLC & 2 & 1 & 3 \\
\hline JCE & 1 & 1 & 2 \\
\hline MSCE & 2 & 3 & 5 \\
\hline \multicolumn{4}{|l|}{ Occupation } \\
\hline Business & 1 & 4 & 5 \\
\hline Intelligence officer & 1 & 0 & 1 \\
\hline Cleaner & 1 & 0 & 1 \\
\hline Hospital attendant & 0 & 1 & 1 \\
\hline Cook & 1 & 0 & 1 \\
\hline Welder & 1 & 0 & 1 \\
\hline \multicolumn{4}{|l|}{ Religion } \\
\hline Seventh day Adventist & 1 & 1 & 2 \\
\hline CCAP & 0 & 1 & 1 \\
\hline Catholic & 2 & 3 & 5 \\
\hline Assemblies of God & 1 & 0 & 1 \\
\hline Mbawa first Christian church & 1 & 0 & 1 \\
\hline \multicolumn{4}{|l|}{ Tribe } \\
\hline Lomwe & 2 & 1 & 3 \\
\hline Ngoni & 2 & 0 & 2 \\
\hline Chewa & 1 & 1 & 2 \\
\hline Yаo & 1 & 0 & 1 \\
\hline Sena & 0 & 1 & 1 \\
\hline Tonga & 1 & 0 & 1 \\
\hline
\end{tabular}

shared by another participant who reported that it kills... do we say the uterus? So that when men's power come, should not have effect in the women's body. Participants also connected the mode of action of Jadelle to the ovulation. Two participants said that Jadelle helps women not to become pregnant by stopping ovulation. One participant also emphasized on the men and women perspectives about the mode of action of Jadelle. She said that it prevents women from getting pregnant when they have sexual intercourse with their husbands.

\subsection{Theme 2: Knowledge about Effectiveness and Efficacy of Jadelle among Men and Women}

The study findings showed that men and women decide to use Jadelle as family planning method because of its effectiveness and efficacy. One male participant said that they just say it is good and it can stay for 5 years while using it. This was supported by a female participant who said that it is best because you do not think of coming 
to the hospital now and then, once inserted for 5 years to come again to the hospital. Male participants also emphasized the effectiveness and efficacy of Jadelle as family planning method when compared to other contraceptives. They said that the method is effective because you can have sex with your wife any how without her getting pregnant unlike the injection. A female participant who had similar views reported that Jadelle is a good method; you can stay for 5 years without any problem. Couples are choosing Jadelle in place of the other contraceptives because it is a long-lasting and reversible. A male participant reported that Jadelle is long acting rather than pills and injection. Pills are used daily and sometimes you forget going to the hospital for injection.

\subsection{Theme 3: Sources of Information about Jadelle}

The findings of the study indicated that participants get information about Jadelle implant from different sources. A male participant reported that he got information about Jadelle from his wife. He said that I came to know Jadelle through my wife who explained the method. On the contrary two female participants said that they got the information from different sources. One said that I heard about Jadelle from a certain staff, one of the sisters from the family planning clinic while the other one said I knew of Jadelle when I came to the hospital for checkup of my baby after 6 weeks of delivery. That was the time they taught us of family planning methods and I choose Jadelle.

Two male participants reported that they heard about Jadelle from the radio. One participant said that the radios and televisions advertised Jadelle as one of the best methods of family planning. We listen to those messages and use them. Another male participant got the information from different source said that $I$ heard about Jadelle from my friends because men share ideas on issues affecting the country when interacting. Ihave heard that there are several family planning methods from my wife and other people.

\subsection{Theme 4: Information Given to Jadelle Users by Providers}

This study showed that participants generally got the information about Jadelle from a health facility especially postnatal and family planning clinics. However, it was also clear from the findings that the information which is given to them is usually inadequate. One male participant said that $I$ would have loved that those health workers were educating people about side effects caused by Jadelle if you do not go along with it and other options which are there. This was supported by a female participant who felt that most women do not know the benefit of Jadelle, if they are taught well and understand they might choose this method. The little information Jadelle users receive from providers give them few options in using the method. This is clearly noticed in statements made by a male participant who said that health workers should have enough time when doing different activities to share this information wherever they are working. People should be helped to understand what they are supposed to do because there are some who look like they know but they do not know and they rely upon this information to reach them.

Some of the responses from participants showed the level of information given to users by providers was confusing. For instance a female participant who was experiencing a problem with Jadelle went to the clinic for advice and the information she was given was very misleading. She reported that I came to complain so that they can remove the implants but I was told that they do not remove before 5 years and even if it is removed I would not stop bleeding. Participants requested that providers should be reaching users in their communities by educating them on the effectiveness of Jadelle, its side effects and its benefits for the individual and the country. This was clear in sentiments made by a male participant who suggested that if they have enough time, they can be moving around in areas educating people because there are some people who have transport problems cannot come to hospitals that are usually far away.

\subsection{Theme 5: Benefits of Jadelle}

In Malawi participants are reportedly testifying that Jadelle has benefits for the individual and the country since its introduction as a family planning method. One male participant narrated that you can have enough space for a mother to care for a child to grow up well, you can have a good time for 5 years. It gives you enough time to do what you want with regard to development of family and the country. Another male participant also said that this family planning method can be one way of reducing deaths of women due to giving birth frequently. A female participant who shared similar sentiments said that if women are not giving birth now and again there are 
going to be enough drugs in the hospitals and women will have time to participate in development project in the country. Participants acknowledged that there are increased dangers associated with having too many children or having children too closely together. One male participant narrated that using Jadelle helps a person to be able to achieve his plans and the woman will be healthy. Because if the woman is giving birth frequently, her body becomes unhealthy. The findings are unique in demonstrating male and female reasons for using the implant Jadelle as a long-lasting contraceptive. This is supported by one male participant who narrated that a person can easily forget to take Oral pills while as for Jadelle once inserted it is done and you just wait for its removal.

\subsection{Theme 6: Challenges Associated with Jadelle}

The findings of this study revealed that there are challenges associated with Jadelle which influence couples' use of Jadelle. One male participant said that his spouse had a problem of continuous menstruation week in week out without stopping. Another male participant with a different experience reported that the cessation of menstruation causes problems in his spouse such as noise from abdomen, her body becomes weak without strength and she suffers from other sicknesses. Participants emphasized on the challenges they faced when using Jadelle. The following is a summary of views of two female participants: Sometimes I miss my monthly periods for a month then the following month I could have it normally. A woman may have monthly period normally whilst to others they have continuous monthly period.

\subsection{Theme 7: Myths Associated with Jadelle}

There are lots of myths associated with the use of implant Jadelle. There are misconceptions associated with insertion procedure or how Jadelle works in the body. Some women believe that the insertion of implants requires major surgery or that insertion is very painful and causes infection. Some male participants commented that the things that they inserted have gone much deeper and after 5 years those things slowly come to the surface but at the moment it's impossible and if they remove it its effect will be there for 5 years because the contraception have already taken its root. Some women believed that implants reduce a woman's libido or affect a couple's sexual life in some way. A female participant said that the husband does not have desire; the woman has no desire because of Jadelle. This view was supported by a male participant who said that since my wife started using Jadelle I can go for a week without having any sexual desires and deep in my heart I have been thinking that this maybe happening because of the method of family planning we are practicing now.

\subsection{Theme 8: Attitudes of Providers of Jadelle}

The findings of this study revealed that some Jadelle users linked their choice to the attitudes of providers. One participant said that I came here telling them that I want the Jadelle removed and they told me that it was impossible. The attitudes of providers can influence a couple decide to use Jadelle or reject it. A male participant also connected attitude of providers to the choice of Jadelle. He said that they did not assess her what they did was just insertion of Jadelle. Some female participants emphasized that attitude of providers also play a decisive role in the choice of Jadelle. There is no pre-insertion counseling and potential disadvantages should be discussed. One female participant said that women are not being taught well and most of them do not know the benefits of Jadelle.

\subsection{Theme 9: Role Played by Men Regarding Use of Jadelle}

The findings of the study also looked at the role played by men regarding the use of Jadelle as a family planning method, in a society which is male dominated. The role of the male is very crucial in the use of contraceptive or the size of the family. A female participant who envisaged that said that had it been that my husband is a trouble maker as of now the marriage could have not been still there. I considered the 5 years as a long period. Men feel positive and wish to be involved in issues about contraceptive used by their partners, discussing contraceptive problems together and resolving the problems. One male participant supported this by saying that most of the times a man is not realistic because he might use a condom when happy and the next day he changes and does not use a condom. This means that he has not followed properly the method of family planning. He even went on to say that they should continue with the same method of family planning, Jadelle, until the time they make up their minds to have another child in future. Since women in the developing countries are either under 
collective decision making with their partners or completely rely on the male partners' decision on issues that affect their reproductive lives. A male participant said that it is good that as a family we made a decision to choose this method of family planning which can go along with her body system and also people should have a right to decide the number of children to bear according to how they see their own family.

\section{Discussion}

This study provided us with valuable information that couples have some knowledge about Jadelle although it is sometimes inadequate and at times inaccurate. They generally knew that Jadelle prevents pregnancy but they did not know its correct mode of action except for one woman. There is evidence that non-barrier method users are generally less knowledgeable about how their current contraceptive method works [13]. This is corroborated by Bogale and colleagues who found that many rural residents lacked knowledge of contraception's mode of action apart from knowing that it prevents pregnancy [14]. The lack of knowledge about mode of action of Jadelle may influence choices of family planning methods among men and women. It is evident that knowledge transfer about the mode of action of the chosen method improves efficiency and compliance to contraceptive method use [13]. As such it is important that family planning providers equip users of Jadelle with correct knowledge about its mode of action to promote effective use of Jadelle and consequently preventing unplanned and unwanted pregnancies.

Participants of this study appreciated the effectiveness of Jadelle as a family planning method in preventing pregnancy. This result is similar to Power et al. [15] who found that women accepted Jadelle as a very effective contraceptive in the prevention of pregnancy when compared to other methods of contraception. This may be attributed to their knowledge about Jadelle. Having better knowledge about family planning methods is associated with decision making power of women to use contraceptives [14]. In this study, couples revealed that they get information about family planning methods from significant others, media and health talks. Nevertheless, men reported that they usually get information about Jadelle from their spouses. Dissimilar results were found in Korea where husbands were the major source of information regarding contraceptive issues [16]. This may be due to differences in culture and levels of male involvement in maternal and child health issues. In Malawi, most men do not attend antenatal and post natal clinics with their spouses where health talks on family planning are given [17]. This is in line with one of the findings of this study whereby unlike men, women mentioned health education at clinics as a source of information. For this reason, it is proper to encourage men to accompany their wives to antenatal, postnatal and family planning clinics so that they can both get correct information about Jadelle. It is evident that many women remembered education they received during antenatal and postnatal health talk and this promoted their utilization of family planning services [18]. Nonetheless, men find it difficult to attend antenatal clinic because it is feminine in nature [17]. Consequently, men do not have access to relevant information about Jadelle from professionals. There is need to de-feminise maternal health services and maternal health education must be given to men and women [17]. Therefore, every opportunity should be utilised at antenatal, postnatal and family planning clinics to teach individuals about family planning because if people accept the advice, they are likely to apply it to their own family [19].

This study also suggests the use of media to complement the dissemination of information about Jadelle to men and women. Radio was reported as one of the main sources of information among participants. There is evidence that media is the most common source of information about contraceptives [20]. Nurses and other health professionals are the least source of family planning information [21]. This is a great concern because nurses are the major contact persons for family planning clients. In this study it was clear that couples were not given adequate information during Pre-insertion and Post-insertion counselling of Jadelle. In addition participants felt that they were not adequately informed by health workers about side effects of Jadelle which caused some women to request removal of the implant. The low and poor contraceptive usage results from ineffective conveyance of relevant information to clients by health care workers [7]. Nurses are well placed to provide relevant information about family planning to people [20] they should intensify one-on-one counselling to all clients so that even illiterate individuals can have adequate information about Jadelle. Counselling is an important aspect in family planning because it allows women to make informed choices about contraceptive methods and ultimately influences their compliance [22].

Some women who participated in this study felt that use of Jadelle allowed them freedom and removed the burden of frequent hospital visits to obtain contraceptives. They were able to continue with their business freely 
because it has long lasting effectiveness. It is evident that women perceive that using contraceptives allows them to take better care of themselves and their family [23] because implants are long acting contraceptives with a high efficacy rate over a 5 years period after insertion [24]. The use of Jadelle has a potential to decrease maternal mortality [25] and its use must be promoted in Malawi where the maternal mortality rate is very high. However, it was clear that some men who participated in this study were not comfortable with the side effects of Jadelle such as menstrual irregularities experienced by their spouses. These men advised their wives to change the method because they felt that the wife was losing too much blood. On the contrary other men perceived that Jadelle did not cause any side effects which were caused by other contraceptives in their wives. This implies that past experiences influence their choice of Jadelle. People do not consider other contraceptives because they have tried them before [26]. Furthermore, myths and misinformation discouraged use of Jadelle among couples in this study. For instance, one female participant reported that if a man sleeps with a woman who is on contraceptives, the power of the contraceptive makes the man weak and loses his sexual power. This is consistent with Okanlawon and colleagues who found that respondents in their study believed that contraceptives are harmful, dangerous and can cause damage to the reproductive system [27]. It is worrisome because Jadelle is not commonly chosen due to inadequate information, possible misinformation and side effects [21]. As such, it is important that couples are provided with correct information if they are going to choose Jadelle.

Participants indicated that the most common side effect of Jadelle that affects them is the disruption of the menstrual cycle such as prolonged menses. Some women are unwilling to use contraceptives due to fear of side effects [28]. It is evident that excessive vaginal bleeding and weight gain are some of the reasons for discontinuation of Jadelle use [26] [29]. Couples should be given adequate information about side effects and benefits of Jadelle so that they are motivated to utilise it. In addition, family planning providers should effectively assist women who are experiencing side effects so that they can continue using Jadelle. Men usually get irritated with prolonged menstruation which occurs in women using Jadelle because in Malawi culture does allow a man to have sex with a woman who is menstruating [3]. Apart from the side effects, this study also revealed that poverty influences the couples' choices on the use of Jadelle because many people in the rural areas cannot afford to pay for transport to attend family planning clinics. Lack of money is a barrier to contraceptive access and use [30]. In a similar study that was conducted by Okanlawon et al. respondents indicated that they experienced difficulties in gaining access to the family planning clinics due to transportation cost and distance [27]. As such efforts must be made to bring family planning services closer to poor communities so that there is improved accessibility of Jadelle. It is clear that women cannot always access Jadelle in many rural health centres in Malawi and this limits the couples' options to choose from.

Participants in the study revealed that the attitudes of individuals towards contraceptives influence their choices. For instance, men demonstrated positive attitudes towards Jadelle as a family planning method. It is evident that men's general attitudes concerning the ideal family size influence women's preferences and opinions [31]. The attitudes of men towards Jadelle may stem from their cultural beliefs. For example, male partners would not want to stop having children if their wives were having only girl children because of the cultural value placed on male offspring and patrilineal heritage [32]. The attitudes of family planning providers also matter because they can serve as motivators or barriers to use of contraceptives among couples. In this study, a participant complained that she was denied the removal of Jadelle when she wanted it removed and this nearly put her marriage in jeopardy. It is necessary that family planning providers should demonstrate positive attitudes because their negative attitudes maybe a barrier to contraceptives utilization [33].

This study provided vital information about participants' decision making regarding contraceptive use. It was clear from the findings that both men and women make decisions on the use of Jadelle as a family planning method. Nonetheless it is evident that men are main decision makers in most African countries such as Malawi and should be involved in prevention of unplanned and unwanted pregnancies [20] [34]. Male involvement in family planning increases uptake of contraceptives [34]. Conversely, men are usually left out when decisions about reproductive health issues are discussed [19]. This may have a negative impact on women's decision to use contraceptives. Sometimes women fail to use contraceptives because of rejection by their spouses [19]. It is important that women in Malawi are empowered to make their own decisions on use of contraceptives. Women who have adequate knowledge about contraceptives have better decision making power about family planning [14]. Thus women should be empowered by providing them with accurate information about contraceptive methods so that they are able to make informed choices. It is encouraging that some men who participated in this study were involved in making decisions about family planning issues. It is evident that men want to be involved in 
open discussion about types of contraceptives used by their partners, their side effects and playing a role in resolving problems arising from contraceptive failures [20].

\section{Conclusion}

In conclusion, this study found that both men and women generally lacked knowledge about the mode of action of Jadelle as a family planning method. They reported that their main sources of information about family planning methods were significant others, media and health talks. Nonetheless, every opportunity should be utilised at antenatal, postnatal and family planning clinics to teach individuals about family planning. Further to that they must be given adequate information during pre-insertion and post-insertion counselling which might in turn increase utilisation of the implant Jadelle. As such family planning providers should intensify one-on-one counselling to all the family planning clients to ensure that even the women and men can have clear and adequate information about Jadelle. This may allow women and men to make informed choices about the use of Jadelle.

\section{Acknowledgements}

We are grateful to all couples who took part in this study.

\section{References}

[1] National Statistical Office (NSO) and ICF Macro (2011) Malawi Demographic Health Survey 2010. NSO, Zomba, ICF Macro, Calverton.

[2] Quinn, H. and Le May, A. (2008) Introducing the Contraceptive Sino Implant II (Zarin) in Sierra Leone. Marie Stopes International, London.

https://www.k4health.org/sites/default/files/Introducing\%20the\%20Contraceptive\%20Impant\%20to\%20Sierra\%20Leo ne\%20finalDraft\%20HQ.pdf

[3] Chipeta1, E.K., Chimwaza, W. and Kalilani-Phiri, L. (2010) Contraceptive Knowledge, Beliefs and Attitudes in Rural Malawi: Misinformation, Misbeliefs and Misperceptions. Malawi Medical Journal, 22, 38-41. http://dx.doi.org/10.4314/mmj.v22i2.58790

[4] Nyanzi, S., Nyanzi, B. and Kalina, B. (2005) Contemporary Myths, Sexuality Misconceptions, Information Sources, and Risk Perceptions of Bodabodamen in Southwest Uganda. Sex Roles, 52, 111-119. http://dx.doi.org/10.1007/s11199-005-1198-3

[5] Wang, X., Chen, C., Wang, L., Chen, D., Guang, W. and French, J. (2003) Conception, Early Pregnancy Loss, and Time to Clinical Pregnancy: A Population-Based Prospective Study. Fertility and Sterility, 79, 577-584. http://dx.doi.org/10.1016/S0015-0282(02)04694-0

[6] World Health Organization (2007) Unsafe Abortion: Global and Regional Estimates of Incidence of Unsafe Abortion and Associated Mortality in 2003. 5th Edition, World Health Organization, Geneva.

[7] Omo-Aghoja, L.O., Omo-Aghoja, V.W., Aghoja, C.O., Okonofua, F.E., Aghedo, O., Umueri, C., Otayohwo, R., Feyi-Waboso, P., Onowhakpor, E.A. and Inikori, K.A. (2009) Factors Associated with the Knowledge, Practice and Perceptions of Contraception in Rural Southern Nigeria. African Journal of Reproductive Health, 15, 135.

[8] Khunga, S. and Lupick, T. (2011) Malawi: Unsafe Abortions Lead Cause of Maternal Death. Daily Times, 5, 12.

[9] Futures, C. (2008) Analysis of the Operational Policy Barriers to Financing and Procuring Contraceptives in Malawi. Health Policy Initiative, USAID.

[10] Levy, J. (2008) Reaching the Goals of Cairo: Male-Involvement in Family Planning (Carolina Papers on International Health No. 28). Center for Global Initiatives, NC: UNC Global.

[11] Ministry of Health (MOH) (2009) National Sexual and Reproductive Health and Rights Policy. Ministry of Health, Lilongwe.

[12] Munhall, P.L. (2007) Nursing Research: A Qualitative Perspective. 4th Edition, Jones \& Bartlett Publishers, Boston.

[13] Topsever, P., Alvur, T.M., Aladağ, N., Topall, R., Ciğerli, O. and Görpelioğlu, S. (2006) Counselling and Knowledge about Contraceptive Mode of Action among Married Women; A Cross-Sectional Study. BMC Women's Health, 6, 1-6. http://dx.doi.org/10.1186/1472-6874-6-12

[14] Bogale, B., Wondafrash, M., Tilahum, T. and Girma, E. (2011) Married Women'S Decision Making Power on Modern Contraceptive Use in Urban and Rural Southern Ethiopia. BioMed Central Public Health, 11, 42. http://dx.doi.org/10.1186/1471-2458-11-342

[15] Power, J., French, R. and Cowan, F.M. (2012) Subdermal Implantable Contraceptives versus other Forms of Reversi- 
ble Contraceptives or other Implants as Effective Methods for Preventing Pregnancy (Review). http://onlinelibrary.wiley.com/doi/10.1002/14651858.CD001326.pub2/pdf

[16] Wiebe, E.R., Henderson, A., Joyce Choic, J. and Trouton, K. (2006) Ethnic Korean Women’S Perceptions about Birth Control. Contraception, 73, 623-627. http://dx.doi.org/10.1016/j.contraception.2006.02.001

[17] Kululanga, L.I., Sundby, J., Malata, A. and Chirwa, E. (2012) Male Involvement in Maternity Health Care in Malawi. African Journal of Reproductive Health, 16, 145-157.

[18] Duong, D.V., Lee, A.H. and Binns, C.W. (2005) Contraception within Six Month Postpartum in Rural Vietnam: Implications on Family Planning and Maternity Services. European Journal of Contraception and Reproductive Health Care, 10, 111-118. http://dx.doi.org/10.1080/13625180500131527

[19] Ikechebelu, J.I., Joe-Ikechebelu, N.N. and Obiajulu, F.N. (2005) Knowledge, Attitude and Practice of Family Planning among Igbo Women of South-Eastern Nigeria. Journal of Obstetrics and Gynaecology, 25, 792-795. http://dx.doi.org/10.1080/01443610500328231

[20] Maja, T.M. (2007) Involvement of Males in Promoting Reproductive Health. Curationis, 30, 71-76. http://dx.doi.org/10.4102/curationis.v30i1.1054

[21] Monjok, E.E., Smesny, A., Ekabua, J.E. and Essien, E.J. (2010) Contraceptive Practices in Nigeria: Literature Review and Recommendation for Future Policy Decisions. Open Access Journal of Contraception, 1, 9-22. http://dx.doi.org/10.2147/OAJC.S9281

[22] Cremer, M., Ditzian, L., April, A., Peralta, B., Klausner, D., Podolsky, R. and Dierking, E. (2011) Depot-Medroxyprogesterone Acetate Contraception Use among Salvadoran Women: An In-Depth Analysis of Attitudes and Experiences. Journal of Women's Health, 20, 1751-1756. http://dx.doi.org/10.1089/jwh.2010.2264

[23] Frost, J.J. and Lindberg, L.D. (2012) Reasons for Using Contraception: Perspectives of US Women Seeking Care at Specialized Family Planning Clinics. Contraception, 87, 465-472. http://dx.doi.org/10.1016/j.contraception.2012.08.012

[24] Ladipo, O.A. and Akinso, S.A. (2005) Contraceptive Implants. African Journal of Reproductive Health, 9, 16-23. http://dx.doi.org/10.2307/3583156

[25] Stover, J. and Ross, J. (2010) How Increased Contraceptive Use Has Reduced Maternal Mortality. Maternal Child Health Journal, 14, 687-695. http://dx.doi.org/10.1007/s10995-009-0505-y

[26] Kane, R., Brown, S., Parkes, N., Walling, M. and Kallick, S. (2009) Long Acting, Reversible and Permanent Methods of Contraception: Insight into Women's Choice of Method. Quality in Primary Care, 17, 107-14.

[27] Okanlawon, K., Reeves, M. and Agbaje, O.F. (2010) Contraceptive Use: Knowledge, Perceptions and Attitudes of Refugee Youths in Oru Refugee Camp, Nigeria. African Journal of Reproductive Health, 14, 17.

[28] Krakowiak-Redd, D., Ansong, D., Otupiri, D., Tran, S., Klanderud, D., Boakye, I., Dickerson, T. and Crookston, B. (2011) Family Planning in a Sub-District Near Kumasi, Ghana: Side Effect Fears, Unintended Pregnancies and Misuse of a Medication as Emergency Contraception. African Journal of Reproductive Health, 15, 135

[29] French, K. (2009) Long-Acting Reversible Contraceptive. Primary Health Care, 19, 40-46. http://dx.doi.org/10.7748/phc2009.05.19.4.40.c7029

[30] Haider, S., Todd, C., Ahmadzai, M., Rahimi, S., Azfar. P., Morris, J.L. and Miller, S. (2009) Childbearing and Contraceptive Decision Making amongst Afghan Men and Women: A Qualitative Analysis. Health Care for Women International, 30, 935-953. http://dx.doi.org/10.1080/07399330903052129

[31] Ijadunola, M.Y., Abiona, T.C., Ijadunola, K.T., Afolabi, O.T., Esimai, O.A. and OlaOlorun, F.M. (2010) Male Involvement in Family Planning Decision Making in Ile-Ife, Osun State, Nigeria African. Journal of Reproductive Health, 14, 45

[32] Imbuki, K., Todd, C.S., Stibich, M.A., Shaffer, D.N. and Sinei, S.K. (2010) Factors Influencing Contraceptive Choice and Discontinuation among HIV-Positive Women in Kericho, Kenya. African Journal of Reproductive Health, 14, 98-109.

[33] Tilahun, M., Mengistie, B., Egata, G. and Reda, A.A. (2012) Health Workers’ Attitudes toward Sexual and Reproductive Health Services for Unmarried Adolescents in Ethiopia. Reproductive Health, 9, 19. http://dx.doi.org/10.1186/1742-4755-9-19

[34] Shattuck, D., Kemer, B., Gilles, K., Hartmann, M., Ng’ombe, T. and Guest, G. (2011) Encouraging Contraceptive Uptake by Motivating Men to Communicate about Family Planning: The Malawi Male Motivator Project. American Journal of public health, 101, 12-18. http://dx.doi.org/10.2105/ajph.2010.300091 